\title{
Referencial teórico de Paulo Freire na efetivação das tecnologias em saúde no período gestacional
}

\author{
Paulo Freire's Theoretical framework on the effectiveness of health tecnologies in the management \\ period
}

Marco teórico de Paulo Freire en la implementación de tecnologías sanitarias en el período Gestacional

\author{
Altenório Lopes de Sousa Filho \\ ORCID: https://orcid.org/0000-0003-3574-4256 \\ Universidade Estadual Vale do Acaraú, Brasil \\ E-mail: altenoriolopes@gmail.com \\ Ana Beatriz Oliveira do Nascimento \\ ORCID: https://orcid.org/0000-0002-2737-3064 \\ Universidade Estadual Vale do Acaraú, Brasil \\ E-mail: anabeatriz.on31@gmail.com \\ Ana Laricia Monteiro de Souza \\ ORCID: https://orcid.org/0000-0002-2984-9222 \\ Universidade Estadual Vale do Acaraú, Brasil \\ E-mail: lariciamonteiro@gmail.com \\ Ana Thaís Frota Rocha \\ ORCID: https://orcid.org/0000-0001-9242-0237 \\ Universidade Estadual Vale do Acaraú, Brasil \\ E-mail: thaisfrotar@gmail.com \\ Andressa Galdino Carvalho \\ ORCID: https://orcid.org/0000-0001-8952-3366 \\ Universidade Estadual Vale do Acaraú, Brasil \\ E-mail:andressacar22@gmail.com \\ Benedita Shirley Carlos Rosa \\ ORCID: https://orcid.org/0000-0002-9125-3614 \\ Universidade Estadual Vale do Acaraú, Brasil \\ E-mail: shirleyrosa08@gmail.com \\ Bruna Torres Melo \\ ORCID: https://orcid.org/0000-0001-8815-6971 \\ Universidade Estadual Vale do Acaraú, Brasil \\ E-mail: brunatorresmelo@gmail.com \\ Hiara Rose Moreno Amaral \\ ORCID: https://orcid.org/0000-0003-4272-3357 \\ Universidade Estadual Vale do Acaraú, Brasil \\ E-mail: hiara_amaral@hotmail.com \\ Maria Adelane Monteiro da Silva \\ ORCID: https://orcid.org/0000-0001-9660-106X \\ Universidade Estadual Vale do Acaraú, Brasil \\ E-mail: adelanemonteiro@hotmail.com \\ Cibelly Aliny Siqueira Lima Freitas \\ ORCID: https://orcid.org/0000-0002-0585-5345 \\ Universidade Estadual Vale do Acaraú, Brasil \\ E-mail: cibellyaliny@gmail.com
}

\begin{abstract}
Resumo
A gestação é um período muito importante e singular na vida de uma mulher, uma vez que é marcado por modificações físicas e psíquicas que requer atendimento e acompanhamento de profissionais qualificados. Isto posto, este estudo objetiva descrever a experiência de acadêmicos de enfermagem em vivências de educação em saúde com gestantes a partir do referencial teórico Paulo Freire. Trata-se de um estudo descritivo com abordagem qualitativa realizada com gestantes no Centro de Saúde da Família - CSF do bairro Padre Palhano, Sobral- Ceará. Durante as intervenções educativas foram abordados temas como aleitamento materno, direitos da gestante, infecção do trato urinário, partejar, parto normal e cesariana. Considera-se de fundamental importância as atividades realizadas na Estratégia Saúde da Família, haja vista que proporcionou a construção de conhecimentos e troca de saberes, numa perspectiva de problematização e reflexão, contribuindo para o cuidado de gestantes no Sistema Único de Saúde.
\end{abstract}


Palavras-chave: Promoção da saúde; Assistência pré-natal; Educação em saúde; Enfermagem.

\begin{abstract}
Pregnancy is a very important and unique period in a woman's life, since it is marked by physical and psychological changes that require care and monitoring by qualified professionals. Therefore, this study aims to describe the experience of nursing students in health education experiences with pregnant women based on Paulo Freire's theoretical framework. This is a descriptive study with a qualitative approach carried out with pregnant women in the Family Health Center - FHC of the neighborhood Padre Palhano, Sobral - Ceará. During the educational interventions topics such as breastfeeding, pregnant women's rights, urinary tract infection, parturition, normal delivery and cesarean section were addressed. The activities carried out in the Family Health Strategy are considered of fundamental importance, since they provided the construction of knowledge and exchange of knowledge, from a perspective of problematization and reflection, contributing to the care of pregnant women in the Unified Health System.
\end{abstract}

Keywords: Health promotion; Prenatal care; Health education; Nursing.

\title{
Resumen
}

El embarazo es un periodo muy importante y único en la vida de una mujer, ya que está marcado por cambios físicos y psicológicos que requieren la atención y el seguimiento de profesionales cualificados. Por lo tanto, este estudio tiene como objetivo describir la experiencia de los estudiantes de enfermería en las experiencias de educación para la salud con las mujeres embarazadas desde el marco teórico de Paulo Freire. Se trata de un estudio descriptivo con enfoque cualitativo realizado con mujeres embarazadas en el Centro de Salud de la Familia - CSF del barrio Padre Palhano, Sobral - Ceará. Durante las intervenciones educativas se abordaron temas como la lactancia materna, los derechos de las mujeres embarazadas, la infección del tracto urinario, el parto, el parto normal y la cesárea. Se considera de fundamental importancia las actividades realizadas en la Estrategia de Salud de la Familia, ya que proporcionó la construcción de conocimiento y el intercambio de saberes, desde una perspectiva de problematización y reflexión, contribuyendo a la atención de la mujer embarazada en el Sistema Único de Salud.

Palabras clave: Promoción de la salud; Cuidados prenatales; Educación sanitaria; Enfermería.

\section{Introdução}

A gravidez é uma condição que envolve muitos mitos, dúvidas, crenças e expectativas, que podem está diretamente relacionada ao contexto familiar e social. Diante do exposto, é importante que se haja uma intervenção de profissionais de saúde habilitados para esclarecer dúvidas e realizar intervenções que proporcionem uma melhor qualidade de vida, instigue ao autocuidado e atenda a gestante de uma forma holística, de acordo com a Política de Saúde da Mulher (Alves, 2018). À vista disso, é necessário que se tenha a preocupação de se abordar condições que podem vir a acometer negativamente a gestação, e realizar um atendimento humanizado com orientações precisas às gestantes. Nesse contexto, as Estratégias Saúde da Família são muito importantes para a efetivação da promoção da saúde, principalmente em relação às ações promovidas por grupos que possibilita um maior vínculo entre as pessoas e facilita que elas exponham seus anseios, além disso, é um espaço favorável para se desenvolver ferramentas fundamentais para o fortalecimento da prática educativa e resolução de causas preveníveis e evitáveis (Domingues et al., 2018).

Nesse ínterim, o enfermeiro possui um papel muito importante no processo de educação em saúde grupal que não pode deixar de ser enfatizado, pois ele é o profissional que tem mais proximidade com as mães, tendo, assim, um papel crucial no processo de problematização e discussão das abordagens. Pontua-se também que essa prática educativa proporciona benefícios como a diminuição das consultas individuais, a participação ativa do indivíduo e a atenção coletiva (Menezes, 2016). A abordagem dialógica através de práticas educacionais em grupos possibilita uma melhor interação entre as gestantes e os profissionais de enfermagem, sendo perceptível o engajamento no processo do cuidado, visto que os encontros permitem o apoio, a troca de experiências entre as participantes e principalmente a ação-reflexiva da identificação das necessidades visando uma mudança de paradigmas no cenário obstétrico, contribuindo assim para a implementação de uma melhor assistência (Alves, 2019).

Nesse contexto, as obras e pensamentos de Paulo Freire são relacionados a sociedade, ao diálogo, à cultura, a transformação, em que o círculo de cultura se evidencia como referência não só na área de educação, mas também nos campos 
da saúde, já que essa maneira de construir conhecimento facilita o contato entre profissionais e pacientes, fortalecendo a autonomia e o empoderamento tanto do individual quanto do coletivo (Antonini, 2020).

A colaboração do ensino, prática e extensão desenvolvidas na comunidade é fundamental, tendo em vista a relevância dessas estratégias de promoção e prevenção à saúde que ampliem a saúde da gestante e fortaleçam os serviços de saúde. Desse modo, o presente estudo objetiva descrever a experiência de acadêmicos de enfermagem em vivências de educação em saúde com gestantes a partir do referencial teórico Paulo Freire no âmbito da Estratégia de Saúde da Família.

\section{Metodologia}

Trata-se de um estudo descritivo, do tipo relato de experiência fundamentado no referencial teórico de Paulo Freire, acerca de ações realizadas por acadêmicos do $5^{\circ}$ período de enfermagem por meio do módulo de Práticas Interdisciplinares em Ensino, Pesquisa e Extensão II, da matriz curricular do curso de enfermagem da Universidade Estadual Vale do Acaraú (UVA).

A pesquisa qualitativa, determina-se pela experiência e tem como principal foco a Interpretação do pesquisador com suas considerações quanto ao fenômeno estudado (Pereira et al., 2018). À vista disso, a partir do estabelecimento da compreensão, trabalha os pressupostos, buscando ampliar o conhecimento acerca da temática pesquisada (Köche,2011).

As oficinas aconteceram junto a um grupo no qual o público alvo eram mulheres no período gestacional durante o período de maio a agosto de 2019, com encontros que ocorreram de forma sistemática quinzenalmente. As atividades foram realizadas junto aos acadêmicos e profissionais da unidade do Centro de Saúde da Família (CSF) do bairro Padre Palhano, no município de Sobral, Ceará.

Para o desenvolvimento das abordagens grupais utilizou-se o círculo de cultura de Paulo Freire, o qual pressupõe-se que a apropriação desse referencial teórico-metodológico acontece em diferentes estudos da Enfermagem, que ocorrem em contextos e situações diversas e se configura como uma estratégia educacional importante, já que proporciona aos participantes do grupo uma protagonização daquele momento, ou seja, que os mesmos possam ser sujeitos ativos, integrados na reflexão sobre sua realidade e criticamente comunicativos, nessa circunstância, o diálogo é a peça chave para que isso ocorra (Garzon, 2018). Desse modo, os encontros seguiram as etapas do círculo de cultura, sendo elas descrita na Figura 1:

Figura 1. Etapas do Círculo de cultura.

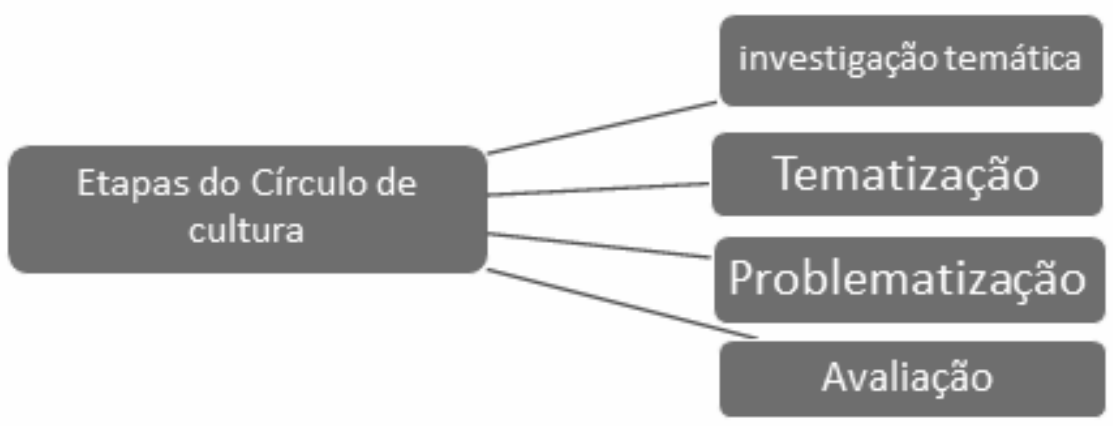

Fonte: Garzon (2018) adaptado.

A elaboração das ações ocorreu a partir da demanda da coordenação do Centro de Saúde da Família e dos relatos das gestantes. A definição de prioridades está diretamente ligada à própria natureza do planejamento, que deve obter a maior pertinência dos planos e a melhor utilização dos recursos. Assim, foram utilizadas metodologias que incluíam recursos 
tecnológicos, visuais, jogos interativos, entre outros. Quanto à sistematização das vivências, é importante salientar que se realizou por meio do diário de campo elaborado pelos mediadores dos encontros que a posteriori permitiu analisar os resultados das ações.

Diante o exposto ressalta-se que o estudo seguiu os preceitos éticos conforme a resolução 466/12 do Conselho Nacional de Saúde sobre pesquisa com seres humanos, assegurando aos participantes os princípios que regem as ações na esfera dos cuidados da saúde, sendo eles: beneficência, não-maleficência, autonomia e justiça ou equidade.

\section{Resultados}

Ao adentrar o serviço de saúde e conhecer um pouco sobre a realidade do território, analisou-se o diagnóstico situacional e realizou-se um planejamento junto à equipe de saúde responsável, a partir da visão crítica dos profissionais da área frente às demandas do CSF e sugestões das gestantes. A partir disso, ao perceber a pouca adesão do público ao grupo, delineou-se a estratégia de distribuir convites pela unidade nas consultas de pré-natal, e por meio das agentes comunitárias de saúde (ACS).

Dessa forma, foram abordadas cinco temáticas relacionadas ao parto, amamentação, direitos das gestantes, infecções do trato urinário e reprodutor, bem como, o partejar conforme o Quadro 1. 
Quadro 1 - Demonstrativo dos encontros realizados com as gestantes no Centro de Saúde Padre Palhano, Sobral-CE, 2021.

\begin{tabular}{|c|c|c|c|}
\hline Encontro & Temáticas & Objetivos & Atividades desenvolvidas \\
\hline $\mathbf{1}^{\circ}$ & $\begin{array}{l}\text { "Parto normal VS cesárea: o } \\
\text { percurso" }\end{array}$ & $\begin{array}{l}\text { Avaliar os conhecimentos das gestantes } \\
\text { sobre os tipos de parto. }\end{array}$ & $\begin{array}{l}\text { Acolhimento: Músicas, pergunta norteadora: O que é o parto? } \\
\text { Desenvolvimento: a identificação das palavras geradoras, construção dos vocábulos, jogo de tabuleiro contendo } \\
\text { perguntas sobre o parto. }\end{array}$ \\
\hline $2^{\circ}$ & $\begin{array}{l}\text { "O que é aleitamento materno } \\
\text { pra você?" }\end{array}$ & $\begin{array}{l}\text { Promover a importância da amamentação } \\
\text { e seus benefícios para a mãe e bebê. }\end{array}$ & $\begin{array}{l}\text { Acolhimento: Músicas, pergunta norteadora: "O que é aleitamento materno pra você?" } \\
\text { Desenvolvimento: Identificação de palavras geradoras para a construção vocabular, exposição de imagens e diálogo } \\
\text { sobre o tema. } \\
\text { Avaliação: distribuição de cartões, para avaliar o encontro. }\end{array}$ \\
\hline $3^{\circ}$ & "Que direito eu tenho?" & $\begin{array}{l}\text { Instruir as gestantes sobre os seus direitos } \\
\text { e deveres. }\end{array}$ & $\begin{array}{l}\text { Acolhimento: Jogo quebra-gelo para familiarização do grupo. } \\
\text { Pergunta norteadora: “que direito eu tenho?” } \\
\text { Desenvolvimento: Construção vocabular das palavras que emergiram, apresentação e exemplificação dos principais } \\
\text { direitos em forma de roda de conversa. } \\
\text { Avaliação: Distribuição de cartões para avaliação. } \\
\text { Identificação dos direitos que as gestantes tinham conhecimentos, foi exibido em slide os direitos que as eram } \\
\text { asseguradas, abrindo um espaço para discussões. }\end{array}$ \\
\hline $4^{\circ}$ & "O que é ITU? mitos e verdades" & $\begin{array}{l}\text { Orientar as gestantes sobre as infecções } \\
\text { do trato urinário e reprodutor, } \\
\text { problematizar a discussão e promover a } \\
\text { troca de experiência entre as gestantes para } \\
\text { o autocuidado destas. }\end{array}$ & $\begin{array}{l}\text { Acolhimento: Músicas, pergunta norteadora: “O que você entende por ITU?". } \\
\text { Desenvolvimento: Construção vocabular das palavras que emergiram, captação dos conhecimentos prévios com um } \\
\text { jogo de mitos e verdades, apresentação dos principais sinais e sintomas, para o incentivo do tratamento precoce. } \\
\text { Avaliação: distribuição de cartões, para avaliar o encontro. }\end{array}$ \\
\hline $5^{\circ}$ & $\begin{array}{l}\text { "Partejar } \\
\text { preparação" }\end{array}$ & $\begin{array}{l}\text { Incentivar práticas de exercícios que } \\
\text { facilitem o trabalho de parto, sobretudo } \\
\text { orientar sobre as condutas do momento do } \\
\text { trabalho de parto. }\end{array}$ & $\begin{array}{l}\text { Acolhimento: Músicas relaxantes que relatavam as fases da gestação com ênfase para o trabalho de parto. } \\
\text { Pergunta Norteadora: Você está preparada para partejar? O que você sabe sobre trabalho de parto? } \\
\text { Objetivo e Desenvolvimento: Detectar o conhecimento de gestantes sobre exercícios que facilitem o trabalho de } \\
\text { parto, foi utilizado práticas de relaxamentos nas gestantes para proporcionar bem-estar, seguido de instrução de } \\
\text { exercícios e de técnicas para estabelecer conforto na hora do parto. } \\
\text { Avaliação: Distribuição de papéis avaliativos e roda de conversa para sugestões voluntárias. }\end{array}$ \\
\hline
\end{tabular}

Fonte: Autores (2021). 


\subsection{Primeiro Encontro "Parto normal VS cesárea: o percurso"}

Objetivo: A temática do encontro foi sugerida pelo grupo de acadêmicos, com o objetivo de fornecer informações e orientações necessárias para as gestantes e respeito da importância de sua participação na tomada de decisão de qual tipo de parto é o desejado por ela e o que é o melhor para seu bebê, bem como os benefícios da participação da gestante nesse processo e também tirar dúvidas a respeito do parto cesáreo e do parto normal.

Acolhimento: A priori, os acadêmicos facilitadores do encontro fizeram uma breve apresentação do grupo, e logo após iniciou-se esta atividade utilizando o referencial teórico-metodológico de Paulo Freire com a pergunta norteadora; O que é o parto? Dentro do universo vocabular das gestantes que estavam presentes surgiu uma miríade de emoções e expectativas; para algumas "o parto é coisa ruim", para outra "O parto é um amor, pois espero nove meses para ver meu filho" e segundo uma outra gestante "é uma dor especial porque é bom. Na ocasião foram colocadas músicas suaves de fundo para proporcionar o relaxamento das gestantes.

Desenvolvimento: Em seguida, de modo dialógico foi sendo construído um momento de conhecimento sobre o parto que culminou com o jogo de tabuleiro, onde no mesmo continha desafios, perguntas e o que uma certa emoção significa para aquela gestante.

Avaliação: Finalizamos o momento com a avaliação do grupo que se deu a partir de folhas de papel onde estavam representados por emojis com emoções positivas, negativas e sugestões. No geral, as gestantes deram feedbacks bastante positivo quanto a dinâmica e pediram para que mais momentos como aqueles fossem ofertados com mais frequência na unidade de saúde, trazendo reflexões de o quão é importante também é a forma com que se traz certas informações e não somente trazê-las, isso é um ponto chave quando se trata de trabalho em grupo, devemos sempre enxergar o indivíduo de forma holística e singular.

\subsection{Segundo encontro "O que é aleitamento materno pra você?"}

Objetivo: A temática foi sugerida pelas próprias gestantes, visando estimulação ao aleitamento materno, orientação dos benefícios para os envolvidos, ensino de técnicas e cuidados, bem como esclarecimento de dúvidas das mães.

Acolhimento: Inicia-se com músicas calmas para proporcionar tranquilidade às mães. A facilitadora do encontro deu boas vindas e logo deu início com a pergunta norteadora: O que é o aleitamento materno para vocês?

Desenvolvimento: As gestantes foram falando o que representava, surgindo os diversos significados em palavras como "dor"; "prazer"; "peito sem leite" e" leite fraco". abrindo espaço para interação com troca de experiências sobre amamentação e discussão. Foram expostas imagens na sala e as gestantes convidadas a escolherem duas imagens que lhe chamassem a atenção. Diante disso, surgiram vários depoimentos, dúvidas, desmistificação de mitos e emoções.

Avaliação: Foram distribuídos cartões para que pudessem avaliar o encontro.

\subsection{Terceiro encontro "Que direito eu tenho?"}

Objetivo: A temática foi sugerida pelas próprias gestantes, visando o conhecimento acerca dos seus direitos antes, durante e após o parto.

Acolhimento: Inicia-se com músicas calmas para proporcionar tranquilidade às mães. Os facilitadores do encontro deram boas vindas com um jogo quebra-gelo para a familiarização do grupo, e logo deu início com a pergunta norteadora: "Que direito eu tenho?", diante disso as gestantes foram falando o que já sabiam previamente sobre o assunto, abrindo espaço para interação com compartilhamento de informações.

Desenvolvimento: Foram expostos alguns dos principais direitos, muitos deles ainda pouco conhecidos pelo grupo. 
Avaliação: Pedimos para que quem quisesse, falasse diante do grupo, destacando uma informação que já tinha conhecimento, e uma informação que ainda não tinha conhecimento, e ao final, distribuímos cartões para a avaliação e sugestões para os encontros subsequentes.

\subsection{Quarto encontro "O que é ITU? mitos e verdades"}

Objetivo: Orientar as gestantes sobre as infecções do trato urinário e reprodutor, problematizar a discussão e promover o compartilhamento de experiências entre as gestantes para o autocuidado destas.

Acolhimento: Inicialmente foram colocadas músicas relaxantes, de forma a proporcionar um ambiente tranquilo. Em seguida, a facilitadora realizou a acolhida, e logo após deu início com a pergunta norteadora: "O que você entende por ITU? ". As gestantes dialogaram sobre o entendimento que estas tinham sobre ITU e surgiram predicados e perguntas como "ardência ao urinar" e "como posso me prevenir?".

Desenvolvimento: A construção vocabular das palavras aconteceu a partir da pergunta norteadora, e adiante, ocorreu a captação dos conhecimentos prévios das gestantes acerca do assunto com um jogo de mitos e verdades, em que houve a troca de experiências entre estas, logo após foram apresentados os principais sinais e sintomas das infecções do trato urinário e vaginoses bacterianas durante a gestação, para o incentivo do tratamento precoce e promoção do autocuidado destas.

Avaliação: Foram distribuídos cartões para que pudessem avaliar o encontro.

\subsection{Quinto encontro "Partejar - exercícios e preparação"}

Objetivo: Detectar o conhecimento prévio das gestantes com assuntos relacionados ao parto, sobretudo o partejar como forma de tornar o momento para elas mais confortável e seguro tendo em vista sua preparação anterior no grupo de gestantes.

Acolhimento: $\mathrm{O}$ tema em questão fazia parte de um receio bastante pertinente para as gestantes do grupo, contudo, foi pensado em um acolhimento com música ambiente mais suave, com aromas relaxantes. Realizamos oficina de sensações para estimulação dos sentidos e desenvolvimento de emoções a partir deles.

Desenvolvimento: Foi montado uma explanação digital interativa com imagens de aparelhos, das maternidades disponíveis na cidade, figuras apresentando os exercícios. A priori, o momento deu início com a chuva de perguntas para sabermos o conhecimento delas em relação ao tema, posteriormente iniciamos a demonstração ativa dos exercícios de parto tais como o de respiração, exercícios antes, durante e depois do parto. As gestantes mostraram-se ativas e confortáveis com o tema, sobretudo, em relação às dúvidas que foram cessadas no momento. $\mathrm{O}$ encerramento ocorreu com a realização de um lanche e distribuição de brindes, fotos e fortalecimento de vínculo entre equipe de saúde e gestantes.

Avaliação: Deu-se através de cartões avaliativos personalizados e também roda de conversa para sugestões voluntárias. Para além disso, em um momento como o feedback fazer o fortalecimento da continuidade dessas mulheres ao grupo e como consequência a vinda de mais mulheres é extremamente viável e necessário para efetivação do mesmo.

\section{Discussões}

No primeiro encontro, a temática abordada foi sobre os tipos de parto, o qual se constitui como um assunto de suma importância para ser comentado durante o pré-natal a fim de orientar as gestantes e esclarecer eventuais dúvidas. O parto é o momento esperado, tendo significados que vão sendo construídos e reconstruídos dinamicamente na cultura em que se inserem as gestantes e também de acordo com as experiências vivenciadas por elas. Ao mesmo tempo, é também um momento temido devido ao desconhecimento do que pode vir a ocorrer. A possibilidade de sentir dor e o medo decorrente disso também são aspectos proeminentes e influentes nas expectativas relacionadas ao parto (Tostes \& Seild, 2016). 
Os relatos das gestantes expressam a preferência ao parto normal, pois os benefícios da recuperação são maiores que a dor, bem como a facilidade para prestar os cuidados ao bebê, e as poucas mulheres que escolheram o parto cesariano foi devido às condições da gestação. Foi perceptível que a maioria delas relacionava o momento com sentimento de afeto intenso como o amor, criação de vínculo, dor acompanhada de felicidade. E após as instruções sobre as técnicas de relaxamento, as mesmas falaram que iriam pesquisar mais medidas que auxiliem em seu conforto no processo de parto.

A proposta do encontro "Parto normal VS cesárea: o percurso", foi a de tentarmos trazer para as gestantes o conhecimento sobre seu estado atual e que seu direito na escolha sobre a autonomia de seu corpo e de como deva ser seu parto deve ser preservado, pois diante das mudanças atuais envolvendo o corpo da mulher, isto reflete no processo de parto e nascimento de seus filhos, de forma que deva haver um aumento do conhecimento sobre a gestação, direito e deveres da gestante, assim como, the proporcionar melhorias na assistência que melhor convenha no processo do parto (Silva et al., 2020).

O momento do parto é um momento ímpar na vida da mulher, esse é um momento que deve ser vivenciado de forma intensa e que também seja ocorrido da forma mais adequada para a parturiente, não podendo este trazer ou vir a trazer riscos nem para a mãe e nem para o bebê, desta forma, o tipo de parto que vai ocorrer deve ser discutido e compartilhado por ela, o poder de escolha e o engajamento da mulher na decisão de seu parto deve ser cada vez mais praticado pelos profissionais que se envolvam no processo, pois o tipo de parto escolhido pela mãe e pelo médico, além disso deve-se salientar em que situação o profissional deseja colocar a mulher no momento de seu parto, como protagonista do processo ou como coadjuvante? Isso implicará em grandes impactos, que percorrerão por longo período sobre a vida da mulher e sobre sua autonomia, quando se trata de seu corpo (Lopes et al., 2019).

No segundo encontro, a sugestão do tema foi oriundo das gestantes, pois relataram dúvidas sobre como proceder a amamentação. $\mathrm{O}$ aleitamento materno traz grandes benefícios à mãe, a criança e a família, e deve ser incentivado principalmente com orientações e estratégias educativas durante os períodos pré e pós-natal mediadas por equipe multidisciplinar de saúde. No entanto, deve ser entendido como a busca do diálogo e o empoderamento, de forma que a mulher adquira autonomia para a realização desta prática (Silva et al.,2017). As orientações dos profissionais, os índices e a duração do aleitamento materno exclusivo podem ser influenciados por essas intervenções (Alves, 2018). Foi uma dinâmica rica em conhecimento e eventuais troca de experiência dos profissionais e das gestantes que já amamentaram. Em sua maioria, as gestantes relataram que era um momento de criação de laços e compartilhamento de sentimentos, o leite materno já contém a nutrição adequada até o sexto mês de vida do bebê. O manejo adequado também favorece a amamentação, entre eles está a pega adequada é um fator que influência a produção de leite, a posição do bebê e da mãe. A amamentação exclusiva foi a mais mencionada, embora diante das dificuldades que poderá surgir no processo, buscaram a unidade básica de saúde para receber orientações e apoio familiar para amamentar e assegurar os benefícios ao bebê.

O tema do terceiro encontro surgiu ao percebermos, por meio de perguntas direcionadas sobre a falta de informação quanto aos direitos atribuídos às gestantes. A disponibilidade das informações poderá favorecer a compreensão em relação aos seus direitos, fazendo com que se sintam respeitadas.

Alguns passos para a realização do parto humanizado e que são considerados como direitos da parturiente são: presença de alguém da família para acompanhar o parto; o recebimento das orientações sobre o parto e os procedimentos que serão adotados; a liberdade de movimentos durante o trabalho de parto; a escolha da posição para a finalização do parto; e o relaxamento para aliviar a dor e o contato imediato mãe bebê logo após o nascimento. É indispensável o respeito aos desejos e direitos da parturiente, incluindo conforto, segurança e bem-estar, assim como controle adequado da dor no trabalho de parto e a presença de um acompanhante escolhido pela mulher.

Humanizar o parto é dar liberdade de escolhas à mulher e prestar atendimento focado em suas necessidades, de forma a atentar-se a singularidades do processo de parto das mesmas e qualificar essa assistência. Possati et al. (2017) reiteram ainda 
que compreender as nuances do parto humanizado e seus aspectos positivos na vida da mulher é ter um posicionamento significativo para a atenção das necessidades de saúde da população.

Os direitos trabalhistas estão presentes na Consolidação das Leis de Trabalho. O artigo diz que a mulher se encontrar em estado de gravidez não constitui motivo para rescisão do contrato de trabalho; a gestante empregada tem direito à licençamaternidade sem prejuízo empregatício; poderá ocorrer transferência de função, quando as condições de saúde o exigirem, assegurada a retomada da função anteriormente exercida, logo após o retorno ao trabalho; entre outras.

Além dos direitos ligados à saúde e ao trabalho, as gestantes também têm acesso a privilégios voltados à esfera social, como atendimento prioritário não apenas em espaços públicos, mas também em locais como bancos e supermercados, além de preferência no transporte público. O objetivo dessas leis é garantir, sobretudo, o menor número de danos possível à saúde da mãe e do filho em desenvolvimento. As gestantes presentes no grupo se mostraram surpresas diante de algumas leis que asseguram os seus direitos.

O quarto encontro abordou Infecções do Trato Urinário (ITU) e Vaginoses Bacterianas durante a gestação, tema sugerido pela gerente da unidade de saúde, devido à grande incidência desse agravo à saúde feminina. Como ITU compreendese a presença e multiplicação de bactérias maléficas no trato urinário, provocando danos aos tecidos do sistema. Por anos, a gravidez foi vista como fator predisponente a todas as formas dessa infecção. Hoje, após estudos sobre as alterações morfofisiológicas do corpo feminino durante o período gravídico, sabe-se que ela, como evento isolado, não é responsável por maior incidência de infecção urinária. (Souza et al., 2020)

Na gestação, algumas alterações próprias do trato genital inferior nesse período, como a hipertrofia das paredes vaginais, o aumento do fluxo sanguíneo e da temperatura, o aumento da imunidade não específica e da acidez vaginal, apesar de terem função protetora sobre o útero, a gravidez e o feto, podem predispor à aquisição de infecções vaginais, requerendo uma atenção especial no período pré-natal de baixo risco, com a finalidade de esclarecer as alterações de flora vaginal e prevenir a transmissão vertical (Silva et al., 2019)

O referido momento foi conduzido a partir da pergunta norteadora “o que você entende por ITU?" e, em seguida, com um jogo de perguntas e respostas de mitos e verdades, estes tiveram a finalidade de avaliar o grau de informação dos integrantes do grupo sobre o assunto, transmitir orientações corretas de saúde assim como promoção do diálogo e troca de experiências. As gestantes se mostraram muito bem orientadas sobre higiene íntima e sintomas típicos de cada patologia, sabendo responder corretamente todas as questões.

A valorização do diálogo favorece o compartilhamento de conhecimentos popular e técnico, ultrapassando o modelo de palestras e promovendo a ativa participação das gestantes no cuidado. Diante disso, a realização de ações educativas com temáticas que contribuam às gestantes, fortalece a compreensão destas quanto ao bem estar próprio e do bebê. (Andrade et al., 2016).

O quinto tema abordado durante os encontros foi relacionado aos tipos de exercícios realizados durante a gestação e durante o trabalho de parto. As evidências disponíveis indicam que o tipo mais favorável de intervenção com exercícios, pelo menos no que diz respeito aos desfechos de saúde materna, é uma combinação de exercícios aeróbicos e resistidos. (Ferreira et al., 2019).

A hospitalização do parto em consonância à criação de maternidades favorecendo um ambiente para o trabalho de parto se respaldou pela grande redução de danos e óbitos para o binômio mãe e filho, todavia, há um grande negativismo neste aspecto, tendo em vista a quebra da individualidade e autonomia da gestante (Souza et al., 2019). Nesse aspecto, favorecer e fortalecer a autonomia e individualidade da mulher no momento do parto antes mesmo do mesmo acontecer é extremamente necessário para uma conduta eficaz e humanizada para a gestante. É imprescindível o preparo para tornar a mulher ciente das circunstâncias, sobretudo, a respeito da relação equipe e parturiente. 
Os benefícios da mobilidade das parturientes durante o trabalho de parto são o aumento da tolerância à dor, diminuição do uso de drogas, melhora da evolução da dilatação e diminuição da duração do trabalho de parto ativo (Canesin \& Amaral, 2010).

A bola suíça é uma das estratégias para a promoção da livre movimentação da mulher durante o parto. Entre os principais benefícios trazidos por exercícios com a bola na gravidez e no trabalho de parto, estão a correção da postura, o relaxamento e alongamento e o fortalecimento da musculatura. (Silva et al., 2011).

A Humanização do parto implica para que a equipe de saúde respeite os aspectos fisiológicos e emocionais da mulher, tornando ela a protagonista do trabalho de parto, sobretudo respeitando os aspectos sociais e a cultura de parto que aquela mulher carrega, favorecendo a não realização de condutas invasivas e intervenções desnecessárias (Andrade et al., 2017). Atentar-se para o oferecimento de suporte emocional para a parturiente, família e bebê respalda os direitos de cidadania do mesmo e favorece a qualificação do profissional como ser humanizado.

Portanto, tendo em vista a complexidade do partejar e sendo sensível aos receios e anseios da gestante para com este momento, o mesmo deve ser dialogado desde os primórdios da gestação de forma clara, coesa e até mesmo didática. É importante que as mulheres tenham conhecimento dos seus direitos e, além disso, tenham suas vontades e medos respeitados, fazendo com que o profissional tenha a expertise de tranquilizá-la para que no momento do parto o mesmo possa ser conduzido de maneira a garantir os direitos e humanização na conduta.

No grupo de gestantes em questão, o momento do parto era algo que transparecia receios ativos, as mulheres relataram curiosidade e vontade de aprender a amenizar o grande receio delas que gira apenas em volta da dor. Relataram também desconhecer métodos de relaxamento durante o trabalho de parto. Assim, destaca-se a importância de entender o partejar como um processo de preparação física, emocional e psicológica, com vistas a qualificar o cuidado do binômio mãe-filho.

\section{Considerações Finais}

As tecnologias educativas utilizadas com as gestantes por meio da aplicação do referencial teórico de Paulo Freire, proporcionou a construção de conhecimentos e o compartilhamento de saberes, numa perspectiva de problematização e reflexão de forma a desenvolver novas percepções, estimulando a adoção de novas práticas. As gestantes puderam por meio das intervenções expressar seus sentimentos, dúvidas, preocupações, expectativas e situações vividas. Desta forma, contribuiu para a reflexão do autocuidado e prevenção de riscos.

As metodologias oportunizaram a aplicação das abordagens grupais, por se configurar como um importante espaço de fala concedido às gestantes, o qual favoreceu uma boa adesão aos grupos.

A curricularização da prática, ensino e extensão no curso de Enfermagem da UVA desponta de forma essencial para a formação de competências do enfermeiro, visto que abrange a possibilidade de desenvolver as extensões universitárias, que fortalecem a participação dos acadêmicos nos serviços de saúde e a interação com o público participante. Além disso, evidenciase que as ações de promoção à saúde da gestante são relevantes, já que estas vivenciam um período significativo e singular em suas vidas, e que estão inseridas em um contexto permeado por dúvidas e anseios a respeito das transformações biológicas e psicossociais. Ademais, carecem de conhecimento relativo aos seus direitos da gestante perante o seu emprego, no período gravídico, no momento do parto e no pós-parto.

Dentre as limitações que envolveram a vivência, aponta-se a violência presente no território, as vulnerabilidades e a falta de adesão das gestantes às atividades grupais em alguns encontros. Ressalta-se que apesar disso, buscou-se sempre as melhores estratégias para enfrentar as adversidades. 
Sugere-se o desenvolvimento de novos estudos que busquem identificar a percepção das mães durante o puerpério, bem como ações intervencionistas que possam fortalecer o cuidado da gestante e do recém-nascido com a inclusão dos pais nesses momentos grupais de promoção à saúde materno infantil.

\section{Referências}

Alves, F. L. C., et. al. (2019). Grupo de gestantes de alto-risco como estratégia de educação em saúde. Rev. Gaúcha de Enferm., 40, e20180023. https://doi.org/10.1590/1983-1447.2019.20180023.

Alves, J. S., et. al. (2018). Orientações sobre amamentação na atenção básica de saúde e associação com o aleitamento materno exclusivo. Ciência \& Saúde Coletiva, 23(4), 1077-1088. https://doi.org/10.1590/1413-81232018234.10752016.

Andrade, J., et al. (2016) Aleitamento materno: Abordagem grupal do Pet-Saúde em um grupo de gestantes com base no Círculo de Cultura de Paulo Freire. Revista Destaques Acadêmicos, 8(3), 38-49. http://dx.doi.org/10.22410/issn.2176-3070.v8i3a2016.1153.

Andrade, et al. (2017). Práticas dos profissionais de enfermagem diante do parto humanizado. Rev. enferm. UFPE online. 11(6), 2576-2585. https://doi.org/10.5205/1981-8963-v11i6a23426p2576-2585-2017.

Antonini, F. O., \& Heideman, I. T. S. B. (2020) Paulo Freire's research itinerary: contributions for promoting health in the teaching profession. Rev. Bras. Enferm., 73(4), :e20190164. https://doi.org/10.1590/0034-7167-2019-0164.

Canesin, K. F., \& Amaral, W. N. (2010). Atuação fisioterapêutica para redução do tempo de trabalho de parto: revisão da literatura. Femina; 38 (8), $429-33$.

Domingues, F. et. al. (2018). Grupo de gestantes na atenção básica: espaço para construção do conhecimento e experiências na gestação. Revista da Faculdade de Ciências Médicas de Sorocaba, 20(3), 150-154. https://doi.org/10.23925/1984-4840.2018v20i3a6.

Ferreira, C. L. M., et al. (2019) Exercise in Pregnancy: The Impact of an Intervention Program in the Duration of Labor and Mode of Delivery. Rev. Bras. Ginecol. Obstet., 41(2), 68-75. https://dx.doi.org/10.1055/s-0038-1675613.

Garzon, A. M. M. et. al. (2018). A pedagogia crítica libertadora de Paulo Freire na produção científica da Enfermagem 1990-2017. Revista Brasileira de Enfermagem., 71(4), 1751-1758. https://doi.org/10.1590/0034-7167-2017-0699.

Köche, J. C. (2011). Fundamentos De Metodologia Científica (34th ed.). Vozes Ltda. http://www.brunovivas.com/wp-content/uploads/site s/10/2018/07/K\%C3\%B6che-Jos\%C3\%A9-Carlos0D0AFundamentos-de-metodologia-cient\%C3\%ADfica-_-teoria-da0D0Aci\%C3\%AAncia-e-inicia\%C3\% A7 \%C3\%A3o-\%C3\%A0-pesquisa.pdf.

Menezes, K. K. P., \& Avelino, P. R. (2016). Grupos operativos na Atenção Primária à Saúde como prática de discussão e educação: uma revisão. Cadernos Saúde Coletiva, 24(1), 124-130. 10.1590/1414-462X201600010162.

Pereira, A. S., Shitsuka, D. M., Parreira, F. J., \& Shitsuka, R. (2018). Metodologia da pesquisa científica. Núcleo de Tecnologia Educacional - NTE., https://repositorio.ufsm.br/bitstream/handle/1/15824/Lic_Computacao_Metodologia-Pesquisa-Cientifica.pdf?sequence=1 .

Possati, A. B., et al. (2017). Humanização do parto: significados e percepções de enfermeiras. Escola Anna Nery Revista de Enfermagem., 21(4), 1-6. https://doi.org/10.1590/2177-9465-ean-2016-0366.

Silva, et al. (2017). Práticas educativas segundo os "Dez passos para o sucesso do aleitamento materno" em um Banco de Leite Humano. Ciência \& Saúde Coletiva, 22(5), 1661-1671. https://doi.org/10.1590/1413-81232017225.14442015.

Silva, et al. (2020). Práticas de assistência à saúde no Brasil e o exercício da autonomia das mulheres no trabalho de parto e nascimento. Research, Society and Development, 9(12), e4191210717. http://dx.doi.org/10.33448/rsd-v9i12.10717.

Silva, et. al. (2011). Uso da bola suíça em trabalho de parto. Acta Paul Enferm.; 24 (5), 656-662. http://dx.doi.org/10.1590/S0103-21002011000500010.

Silva, et. al. (2019). Infecção do trato urinário na gestação: diagnóstico e tratamento. Revista Científica da Faculdade de Educação e Meio Ambiente., 10(1), p. 71-80. https://doi.org/10.31072/rcf.v10iedesp.765.

Souza, et. al. (2020). Infecção do trato urinário (ITU) na gestação: deficiências múltiplas x aborto. Rev. Saúde e Meio Ambiente., 10(1), 19-31.

Souza, et. al. (2019). Tecnologias apropriadas ao processo do trabalho de parto humanizado. Enferm Foco, 10(2), 118-124. https://doi.org/10.21675/2357707X.2019.v10.n2.2180.

Tostes, N. A., \& Seidl, E. M. F. (2016). Expectativas de gestantes sobre o parto e suas percepções acerca da preparação para o parto. Temas em Psicologia, 24(2), 681-693. http://dx.doi.org/10.9788/TP2016.2-15. 